\title{
REMOVAL OF PHENOLIC COMPOUNDS FROM AQUEOUS SOLUTIONS BY BIOSORPTION ONTO $A C A C I A$ LEUCOCEPHALA BARK POWDER: EQUILIBRIUM AND KINETIC STUDIES
}

\author{
NADAVALA SIVA KUMAR* AND KIM MIN \\ Department of Safety Environmental System Engineering, Dongguk University, Gyeongju 780-714, \\ Republic of Korea \\ (Received: March 31, 2010 - Accepted: December 17, 2010)
}

\begin{abstract}
The aim of this work is to determine the potential application of Acacia leucocephala bark powder as a biosorbent for removing phenolic compounds from aqueous solutions. Experiments were carried out as function of initial pH (2-10), contact time, initial concentration of adsorbate (100-400 mg/L), and effect of adsorbent dosage. Adsorption of phenolic compounds (phenol, 2-chlorophenol (2- $\mathrm{CPh}$ ) and 4- chlorophenol (4-CPh)) from aqueous solutions on bark powder was studied under batch equilibrium conditions. Maximum phenol removal was observed at $\mathrm{pH}$ 7.0. Increase in the $\mathrm{pH}$ to above neutrality resulted in the decrease in the phenolic compounds adsorption capacity. The adsorption process was fast, and it reached equilibrium in 4-h contact time. The kinetics study demonstrated that the adsorption process proceeded according to the pseudo-first-order kinetic model. Three isotherm models (Langmuir, Freundlich and Dubinin-Radushkevich) were employed in the analysis of the adsorption equilibrium data. The data fitted well with the Langmuir isotherm. The Langmuir model resulted in the best fit and the new adsorbent had maximum adsorption capacities for phenol, 2-CPh and 4-CPh of 94.33, 147.05 and $181.81 \mathrm{mg} / \mathrm{g}$, respectively. The results indicated that the $A$. leucocephala bark powder could be an alternative for more costly adsorbents used for removal of phenolic compounds from aqueous media.
\end{abstract}

Keywords: Adsorption, Acacia leucocephala bark powder, Phenolic compounds, Kinetics and Isotherm models.

\section{INTRODUCTION}

The introduction of toxic pollutants can have a several impact on many organisms that live not only in aquatic ecosystem but also in the body of the human beings. ${ }^{1}$ They exist in different concentrations in wastewaters disposed from many industrial processes, including petrochemical industry, coking, synthetic rubber, plastics, paper, oil refineries, as well as phenolic resin industries. ${ }^{2,3}$ Phenol and its derivatives are considered as noxious pollutants, because they are toxic and harmful to living organisms even at low concentrations. ${ }^{4}$ The utilization of phenol contaminated waters causes protein degeneration, vomiting, tissue erosion, smoky colored urine, paralysis of the central nervous system and also damages the kidney, liver and pancreas in human bodies. ${ }^{5}$ According to the recommendation of World Health Organization (WHO), the permissible concentration of phenolic contents in potable waters is $1 \mu \mathrm{g} / \mathrm{L}$ and the regulations by the Environmental Protection Agency (EPA), call for lowering phenol content in wastewaters less than 1 $\mathrm{mg} / \mathrm{L} .^{6,7}$ Thus, it is fully recommended to removal of phenolic compounds from industrial effluents before entering in to the water stream.

In recent years; interest has been focused on the removal of phenols from aqueous solution. Traditionally, biological treatment, activated carbon adsorption, solvent extraction, chemical oxidation and electrochemical methods are the most widely used methods for removing phenol and phenolic compounds from wastewaters. ${ }^{8}$ Activated carbon is one of the most effective ones, as it has a porous structure and provides a good capacity for the adsorption of organic compounds due to its high surface area., ${ }^{910}$ However, activated carbon has a number of disadvantages, such as relatively high cost, expensive cost and considerable loss during chemical or thermal regeneration of spent carbon. This has led many researchers to search for more cost-effective and efficient adsorbents to remove organic contaminants from water and wastewater. Fly ash, ${ }^{11}$ rice husk,${ }^{12}$ peat, ${ }^{13}$ bentonite,,${ }^{14}$ and polymeric adsorbents ${ }^{15,16}$ have been tested for the adsorption of organic pollutants. The search for new and innovative treatment techniques has focused attention on the adsorption capacities of other adsorbents, such as agricultural by-products and lignocellulosic residues, ${ }^{17-19}$ which are readily available and do not need to be regenerated due to their low cost. Numerous studies on the sorption of metals and organic pollutants by these alternative adsorbents in batch systems have been reported. ${ }^{17,20}$ Removal of cadmium and mercury ions from aqueous solution by sorption on treated Pinus pinaster bark: kinetics and isotherms was studied by Vazquez et al. ${ }^{21}$ Regarding to the sorption of organic pollutants by pine bark reported interesting results for organochlorine pesticides. ${ }^{22}$ Adsorption of phenol on formaldehyde-pretreated Pinus pinaster bark: equilibrium and kinetics was studied by Vazquez et al. ${ }^{23}$
Acacia leucocephala bark, agricultural and easily available waste, could be an alternative for more costly wastewater treatment processes. Acacia leucocephala's native range through South and Southeast Asia is noncontiguous. Its largest continuous distribution is arid India through Sri Lanka, Bangladesh, Burma and much of Thailand. Acacia leucocephala is an important dry-season fodder and pasture tree throughout its range. Leaves, tender shoots and pods are eagerly eaten by goats, sheep and cattle. All mature acacia leucocephala put on an annual layer of bark, which contributes to the increasing diameter of the stems. In some species the outermost layer dies and is annually deciduous either in long strips or in variably sized flakes. Due to the high number of Acacia leucocephala trees in India, massive amount of bark is produced, which is being disposed off as waste. Lignocellulosic wastes materials are available in abundance, renewable and low in cost. The Acacia leucocephala bark fulfils these requests its potential has been under estimated. A few studies were published suggesting good efficiencies in heavy metals removal from aqueous solution by Acacia leucocephala bark. ${ }^{24,25}$ In the interest of the environment, according to authors' survey, there is no extensive study on the biosorptive removal of phenolic compounds from aqueous solutions using A. leucocephala bark biomass in literature. In addition, this material was chosen as novel biosorbent in this study due to being of its naturally abundant, renewable and thus cost-effective biomass.

The aim of this present work is to investigate the biosorption potentiality of A. leucocephala bark powder biosorbent material for the removal of phenol, 2-CPh and 4-CPh from aqueous medium. The A. leucocephala bark powder was characterized by scanning electron microscopy (SEM). Further this $A$. leucocephala bark powder was characterized before and after adsorption of phenolic compounds by Fourier Transform Infrared (FTIR) spectroscopy studies. The effect of various factors, such as time of contact, biosorbent dosage, $\mathrm{pH}$ and initial adsorbate concentrations on this biosorption process was investigated under batch equilibrium technique. Moreover, kinetic and equilibrium models were used to fit experimental data.

\section{MATERIALS AND METHODS}

\section{Materials}

Acacia leucocephala bark was collected from a local Acacia leucocephala tree near Pullampet, Kadapa District, Andhra Pradesh, India, for the preparation of biosorbent. Required raw materials, Phenol (Junsei Chemical Co. Ltd (Tokyo, Japan), 2-CPh and 4-CPh (Junsei Chemicals Co., Korea) were used without further purification. Stock solutions were prepared by dissolving $1.0 \mathrm{~g}$ of phenol, 2-CPh and 4-CPh individually in one liter of double distilled water. These stock solutions were used to prepare $100,200,300$, and $400 \mathrm{mg} / \mathrm{L}$ solutions of phenol, 2-CPh and 4-CPh. $0.1 \mathrm{M} \mathrm{HCl}$ and $0.1 \mathrm{M} \mathrm{NaOH}$, used 
to adjust $\mathrm{pH}$, were obtained from Samchun Chemicals, South Korea. Water used for preparation of solutions and cleaning adsorbents was generated in the laboratory by double distilling the deionized water in a quartz distillation unit.

\section{Preparation of biosorbent}

Acacia leucocephala bark was thoroughly washed with distilled water to remove mud and dirt. Then A. leucocephala bark powder was soaked in $0.1 \mathrm{M}$ $\mathrm{NaOH}$ to remove lignin based color materials followed by $0.1 \mathrm{M} \mathrm{H}_{2} \mathrm{SO}_{4}$. Finally it was washed with distilled water several times and dried in an oven at $80^{\circ} \mathrm{C}$ for $6 \mathrm{~h}$ and cooled at room temperature in desiccators. The physical, chemical and surface characterization of $A$. leucocephala bark powder is carried out using standard methods and the results are given in Table 1 . The dried $A$. leucocephala bark powder was stored in desiccators until used. The dried bark was ground to fine powder and used as biosorbent without any pretreatment for phenolic compounds adsorption.

Table 1. Physical, chemical and surface characterization of Acacia leucocephala bark powder.

\begin{tabular}{|l|l|}
\hline Parameter & Value \\
\hline Color & Light Yellowish \\
\hline Odour & None \\
\hline Weight loss (\%) & 54.8 \\
\hline Apparent (bulk) density $\left(\mathrm{g} / \mathrm{cm}^{3}\right)$ & 0.251 \\
\hline Moisture content $(\%)$ & 7 \\
\hline Ash content $(\%)$ & 4.88 \\
\hline BET Surface are $\left(\mathrm{m}^{2} / \mathrm{g}\right)$ & 0.27 \\
\hline Carbon $(\%)$ & 44.8 \\
\hline Hydrogen $(\%)$ & 5.65 \\
\hline
\end{tabular}

Analysis of phenolic compounds

The concentration of phenol, 2-CPh and 4-CPh, in aqueous medium was determined by measuring absorbance at wavelengths of $270 \mathrm{~nm}, 274 \mathrm{~nm}$ and $280 \mathrm{~nm}$, respectively, Using UV-Spectrophotometer (Shimadzu UV-1601 Spectrophotometer, Japan). In order to reduce measurement errors in all the experiments, UV absorption intensity of each solution sample was measured in triplicates and the average value was used to calculate the equilibrium concentration based on standard calibration curve, whose correlation coefficient square $\left(\mathrm{R}^{2}\right)$ was 0.999 . The experimental error was observed to be within $\pm 2 \%$.

Batch studies

Adsorption experiments were conducted by varying $\mathrm{pH}$, contact time, adsorbent dosage and adsorbate concentration. In adsorption equilibrium, experiments were conducted in a set of $125 \mathrm{~mL}$ Erlenmeyer flasks, where solutions of phenolic compounds $100 \mathrm{~mL}$ (phenol, 2-CPh and 4-CPh) with different initial concentrations $(100-400 \mathrm{mg} / \mathrm{L})$ were added in these flasks. The $\mathrm{pH}$ of solution was maintained at a desired value by adding $0.1 \mathrm{M} \mathrm{NaOH}$ or $\mathrm{HCl}$. Equal masses of $0.4 \mathrm{~g} / 0.1 \mathrm{~L}$ of $A$. leucocephala bark powder were added to phenolic compounds solutions and each sample was kept in a shaking Water Bath Temperature controller of $220 \mathrm{rpm}$ at $25 \pm 1^{\circ} \mathrm{C}$ for $4 \mathrm{~h}$ to reach equilibrium of the solid-solution mixture. Samples were taken out from flasks and the solutions were separated from the adsorbent by filtered through Whatman No.50 filter paper $(2.7 \mu \mathrm{m}$ size particle retention) to eliminate any fine particles. Then the concentration of phenolic compounds was determined by measuring absorbance using UV-Vis spectrophotometer (Shimadzu UV/Vis1601 Spectrophotometer, Japan) at $270 \mathrm{~nm}, 274 \mathrm{~nm}$ and $280 \mathrm{~nm}$ for phenol, $2-\mathrm{CPh}$ and $4-\mathrm{CPh}$, respectively. The amount of adsorption at equilibrium, qe $(\mathrm{mg} / \mathrm{g})$ and the percent adsorption (\%) was computed as follows:

$$
\begin{aligned}
q_{e} & =\frac{\left(C_{0}-C_{e q}\right) V}{m} \\
\text { Percent adsorption } \quad(\%) & =\frac{C_{0}-C}{C_{0}} \times 100
\end{aligned}
$$

where $C_{0}$ and $C_{\text {eq }}(\mathrm{mg} / \mathrm{L})$ are the liquid-phase concentrations of phenolic compounds at initial and equilibrium, respectively. $V(\mathrm{~L})$ is the volume of the solution, $m$ is the mass $(\mathrm{g})$ of the bark powder and $C$ the phenolic compounds concentrations at the end of adsorption.

The procedures of kinetic experiments were basically identical to those of equilibrium tests. The aqueous samples were taken at preset time intervals and the concentrations of phenolic compounds were similarly measured. The amount of adsorption at time $t, q_{\mathrm{t}}(\mathrm{mg} / \mathrm{g})$, was calculated by

$$
q_{t}=\frac{\left(C_{0}-C_{t}\right) V}{m}
$$

\section{RESULTS AND DISCUSSION}

\section{Characterization of acacia leucocephala bark powder}

\section{Fourier Transform Infrared (FTIR) Studies}

Characterization of the biosorbent was carried out by Fourier Transform Infrared Spectroscopy to determine the type of functional groups on the biosorbent. FTIR spectra in the range of $4000-400 \mathrm{~cm}^{-1}$ for the pure Acacia leucocephala bark powder and the A. leucocephala bark powder loaded with phenol, 2-CPh and 4-CPh are shown in Fig. 1(a), (b), (C) and (d), respectively. The spectra display a number of absorption peaks, indicating the complex nature of the biosorbent material examined. Fig. 1(a)-(d) shows the FTIR spectra had a broad band absorption peaks at $3426 \mathrm{~cm}^{-1}$ corresponding to the overlapping of $-\mathrm{OH}$ and $-\mathrm{NH}$ peaks. On the other hand, the two peaks appear at $2918-2850 \mathrm{~cm}^{-1}$ which represent the asymmetrical and symmetrical stretching vibration of methylene $\left(-\mathrm{CH}_{2}\right)$ group, respectively. The $\mathrm{C}=\mathrm{O}$ stretching of $\mathrm{A}$. leucocephala pure bark powder as at $1613.8 \mathrm{~cm}^{-1}$. The presence of $-\mathrm{C}-\mathrm{O}$ and $-\mathrm{C}-\mathrm{N}$ linkages are confirmed from the peaks at 1321.7 and $1033.2 \mathrm{~cm}^{-1}$. As we observe in Figure 1(b), (c) and (d), a significant difference can be seen in the FTIR spectra of biosorbent before and after adsorption. The FTIR band of $\mathrm{C}=\mathrm{O}$ stretching shifted to higher frequency due to involvement of carboxyl ($\mathrm{C}=\mathrm{O}$ ) group in the adsorption process of phenolic compounds with pure bark powder. This shift and/or broadening of some of the FTIR spectral peaks of the biosorbent in the presence of the phenolic compounds studied provides a clear indication that the functional groups like $-\mathrm{NH}_{2},-\mathrm{OH}$ and $-\mathrm{C}=\mathrm{O}$ present on the A. leucocephala bark powder surface are involved in phenol, 2-CPh and 4-CPh adsorption.

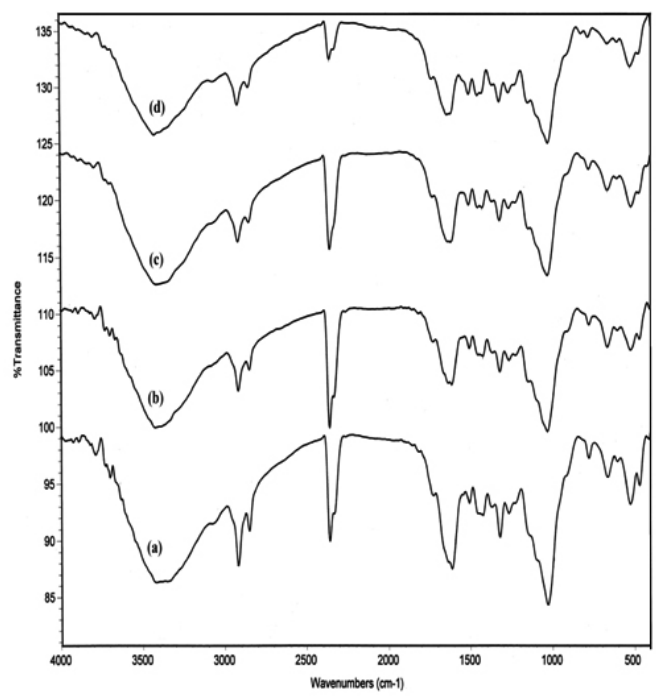

Figure 1. FTIR spectra of phenolic compounds. (a) before biosorption of Acacia leucocephala bark powder (b) after phenol biosorption (c) after 2-CPh biosorption (d) after 4-CPh biosorption.

\section{Scanning electron microscopic (SEM) Studies}

For morphological characteristics SEM of adsorbent A. leucocephala bark powder was carried out. Scanning Electron Microscopy (SEM; Model Evo15, Carl Zeiss, England) is widely used to study the morphological features and surface characteristics of the biosorbent material. In the present study, Scanning electro-micrographs (SEM) show the surface texture and morphology of the biosorbent (Fig. 2a-b). It is evident from the micrograph that the biosorbent has a well-defined rod clusters in net/mat format $(500 \times)$. At $2.50 \times$ magnification, the adsorbent have irregular structure, thus makes possible for the adsorption of phenolic compounds on different parts of the adsorbent. 

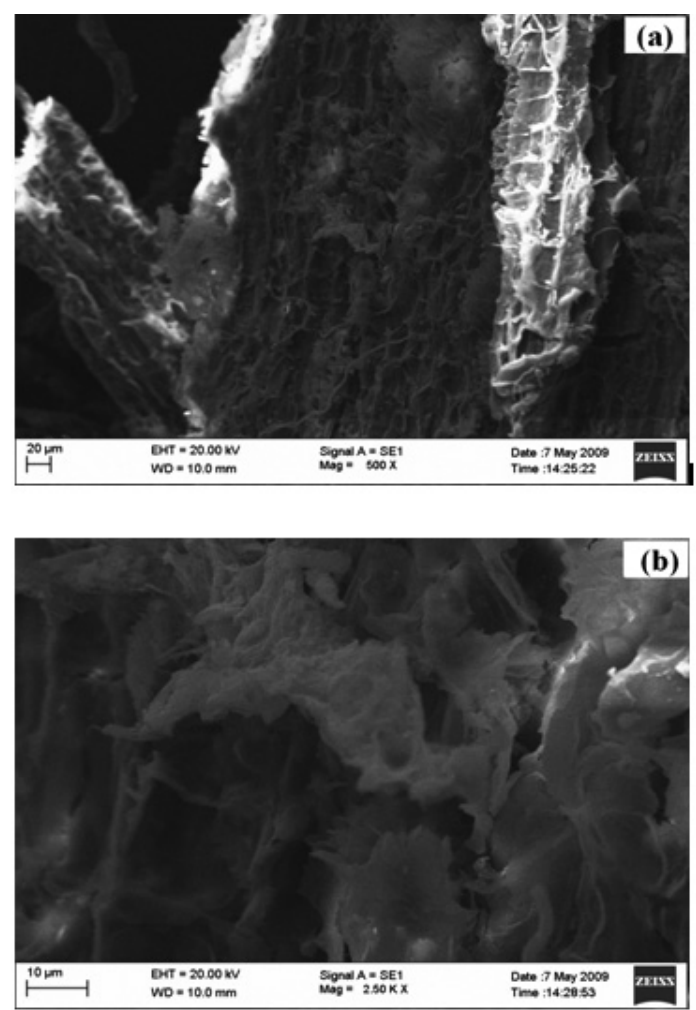

Figure 2. Scanning electron micrographs of the Acacia leucocephala bark powder at (a) 500x and (b) 2.50x magnification.

\section{Effect of $p H$}

The solution $\mathrm{pH}$ is one of the dominant parameters controlling biosorption. Phenolic compounds biosorption onto $A$. leucocephala bark powder as a function of $\mathrm{pH}$ ranging from 2.0 to 10.0 are given in Fig. 3. The removal of phenolic compounds by A. leucocephala bark powder was highly dependent on $\mathrm{pH}$. In order to optimize the $\mathrm{pH}$ for maximum removal efficiency, experiments were conducted in the $\mathrm{pH}$ range from 2.0 to 10.0 using $0.2 \mathrm{~g}$ of A. leucocephala bark powder with $100 \mathrm{ml}$ of $100 \mathrm{mg} / \mathrm{L}$ initial phenolic compounds concentrations at $25 \pm 1^{\circ} \mathrm{C}$. In the alkaline range, the $\mathrm{pH}$ was varied using aqueous $0.1 \mathrm{M}$ $\mathrm{NaOH}$, where as in the acidic range, $\mathrm{pH}$ was varied using $0.1 \mathrm{M} \mathrm{HCl}$. The FTIR spectroscopic analysis showed that the A. leucocephala bark powder has a variety of functional groups, such as carboxyl, hydroxyl and amine and these groups are involved in almost all potential binding mechanisms. Moreover, depending on the $\mathrm{pH}$ values of the aqueous solutions these functional groups participate in phenolic compounds bindings. The maximum adsorption capacities increase with increase in $\mathrm{pH}$ up to $\mathrm{pH} 7$ and decreases there on. It was observed that the relative amount of phenolic compounds adsorbed was significantly affected by $\mathrm{pH}$. The maximum adsorption occurs at neutral $\mathrm{pH}$. Significant decline in removal efficiency was observed for further increase in $\mathrm{pH}$, which may be attributed to formation of phenolate anions. The phenolic compounds considered in this study, viz. phenol, 2- $\mathrm{CPh}$, and 4- $\mathrm{CPh}$, have $\mathrm{pKa}$ values of 9.9, 8.3, and 9.2, respectively. When the $\mathrm{pH}$ of a solution goes beyond the $\mathrm{pKa}$, phenols chiefly exist as negative phenolate ions, whereas they exist as neutral molecules below the $\mathrm{pKa}$. Due to the electron rich nature of the oxygen atom in phenolate ions, the hydrogen bonding efficiency decreases. Therefore, phenols effectively adsorbed on to the adsorbent as molecules but not phenolate ions. From the experimental results, $\mathrm{pH} 7.0$ was selected as an optimum $\mathrm{pH}$ value.

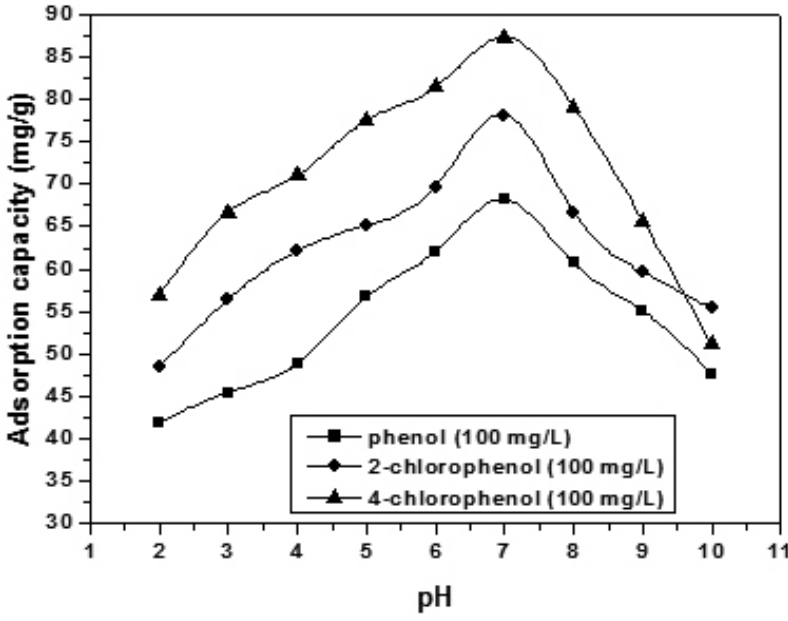

Figure 3. Effect of $\mathrm{pH}$ on the biosorption of ( $\notin)$ phenol, (ऽ) 2-CPh and ( $)$ 4-CPh onto Acacia leucocephala bark powder. Experimental conditions: for phenolic compounds: initial concentrations $=100 \mathrm{mg} / \mathrm{L}$, contact time $5 \mathrm{~h}$, biosorbent dosage $=0.2 \mathrm{~g} / 0.1 \mathrm{~L}, \mathrm{Temp}=25 \pm 1^{\circ} \mathrm{C}$, agitation rate $220 \mathrm{rpm}$.

\section{Effect of biosorbent dosage}

The adsorption of phenol 2-CPh and 4-CPh on A. leucocephala bark powder were carried out at different adsorbent dose by keeping other parameters constants. The relationship between adsorbent dose and substrate removal for same initial concentrations of phenolic compounds is presented in Fig. 4a-c, respectively. It can be seen from Figures that percentage removal of phenol, 2-CPh and 4-CPh increased with the increase in adsorbent dose while loading capacity, $\mathrm{q}_{\mathrm{e}}(\mathrm{mg} / \mathrm{g}$ ), (amount of phenol, 2-CPh and 4-CPh loaded per unit weight of adsorbent) gradually decreased for the same. This increase in loading capacity is due to the availability of higher number of solutes (phenol, 2-CPh and 4-CPh) per unit mass of adsorbent, i.e. higher solute/adsorbent ratio. These experiments were performed with initial concentration of $100 \mathrm{mg} / \mathrm{L}$ of solutes and neutral $\mathrm{pH}$ of the solution. It can also be seen from these Figures that the uptake of solute markedly increased up to adsorbent dose of $0.4 \mathrm{~g} / 0.1 \mathrm{~L}$ and thereafter no significant increase was observed. It can be concluded that the rate of phenolic compounds binding with adsorbent increases more rapidly in the initial stages and after some point the adsorption is marginal and becomes almost constant. Therefore, the optimum biosorbent dosage was taken as $0.4 \mathrm{~g} / 0.1 \mathrm{~L}$ for further experiments.

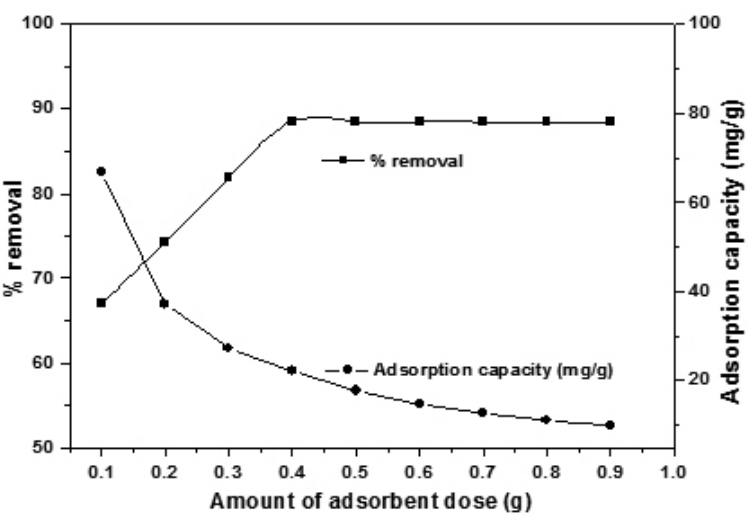

(a) 


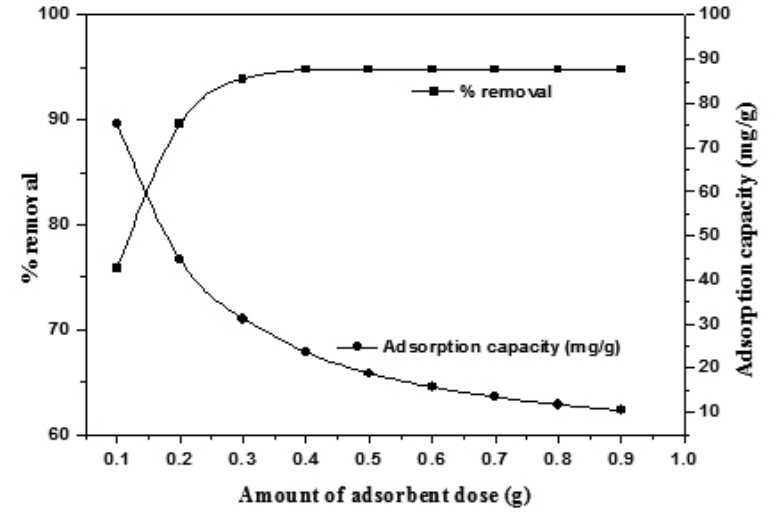

(b)

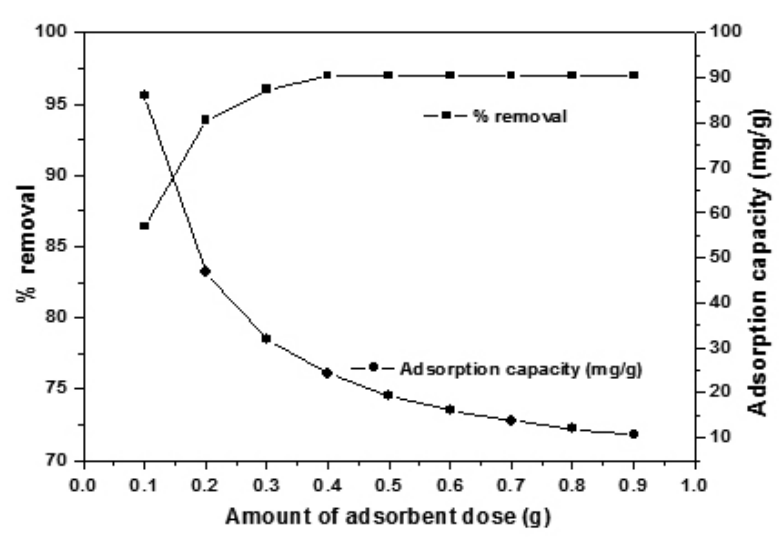

(c)

Figure 4. Effect of biosorbent dosage level on the biosorption of (a) phenol, (b) 2-CPh, and (c) 4-CPh onto Schizophyllum commune fungus [(\% removal of phenol, 2-CPh, 4-CPh and biosorption capacity $(\mathrm{mg} / \mathrm{g})]$ Experimental conditions: for phenolic compounds: initial concentrations $=100$ $\mathrm{mg} / \mathrm{L}$, biosorbent dosage $=0.1-0.9 \mathrm{~g}$, contact time $5 \mathrm{~h}, \mathrm{Temp}=25 \pm 1^{\circ} \mathrm{C}, \mathrm{pH} 7.0$.

\section{Effect of contact time and initial concentration}

The effect of agitation time on the extent of adsorption of phenolic compounds at different concentrations is shown in Figures 5, 6 and 7 for phenol, 2-CPh and 4-CPh, respectively. Effect of shaking time on biosorption of phenolic compounds onto $A$. leucocephala bark powder was studied over a shaking time of 30-300 min, using $0.4 \mathrm{~g} / 0.1 \mathrm{~L}$ of $A$. leucocephala bark powder, $100-400 \mathrm{mg} / \mathrm{L}$ of phenolic compounds concentration at $\mathrm{pH} 7.0,25 \pm 1^{\circ} \mathrm{C}$ and $220 \mathrm{rpm}$ shaking speed. The saturation curves rise sharply in the initial stages, indicating that there are plenty of readily accessible sites. Eventually, a plateau is reached in all curves indicating that the adsorbent is saturated at this level. It can be seen from Figures that the contact time needed for phenol solutions with initial concentrations of $100-400 \mathrm{mg} / \mathrm{L}$ to reach equilibrium was $4 \mathrm{~h}$. Almost, no remarkable improvement was observed after longer contact time. After this equilibrium period, the amount of solute adsorbed did not change significantly with time, indicating that this time is sufficient to attain equilibrium for the maximum removal of phenolic compounds from aqueous solutions by $A$. leucocephala bark powder. So, the optimum contact time was selected as $4 \mathrm{~h}$ for further experiments. However, for adsorbate solutions with higher initial concentrations, lower equilibrium times were required. It was also seen that an increase in initial adsorbates solution concentrations resulted in increased phenolic compounds uptake. The removal curves are single, smooth and continuous, indicating the formation of monolayer coverage of the phenol molecules onto the outer surface of the adsorbent.

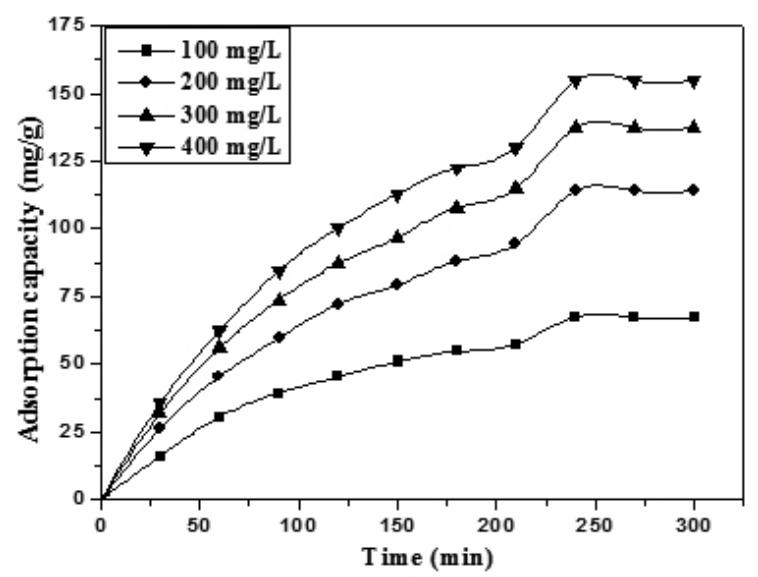

Figure 5. Effect of contact time on phenol biosorption [Different initial phenol concentrations. (c) $\mathrm{C}_{0}=100 \mathrm{mg} / \mathrm{L},(\bullet) \mathrm{C}_{0}=200 \mathrm{mg} / \mathrm{L},(\boldsymbol{\Delta}) \mathrm{C}_{0}=300$ $\mathrm{mg} / \mathrm{L}$, (q) $\mathrm{C}_{0}=400 \mathrm{mg} / \mathrm{L} ; \mathrm{pH}=7.0$; biosorbent dosage $=0.4 \mathrm{~g} / 0.1 \mathrm{~L}$; contact time $4 \mathrm{~h}$, agitation rate: $220 \mathrm{rpm}$, Temp $\left.=25 \pm 1^{\circ} \mathrm{C}\right]$

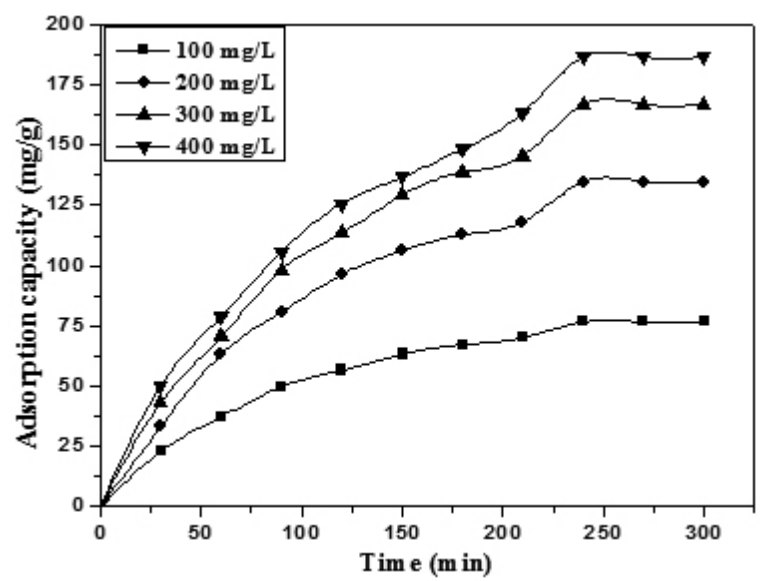

Figure 6. Effect of contact time on 2-chlorophenol biosorption [Different initial 2-CPh concentrations. $(\phi) \mathrm{C}_{0}=100 \mathrm{mg} / \mathrm{L},(\bullet) \mathrm{C}_{0}=200 \mathrm{mg} / \mathrm{L},(\boldsymbol{\Delta}) \mathrm{C}_{0}=$ $300 \mathrm{mg} / \mathrm{L}$, (q) $\mathrm{C}_{0}=400 \mathrm{mg} / \mathrm{L} ; \mathrm{pH}=7.0 ;$ biosorbent dosage $=0.4 \mathrm{~g} / 0.1 \mathrm{~L} ;$ contact time $4 \mathrm{~h}$, agitation rate: $\left.220 \mathrm{rpm}, \mathrm{Temp}=25 \pm 1^{\circ} \mathrm{C}\right]$

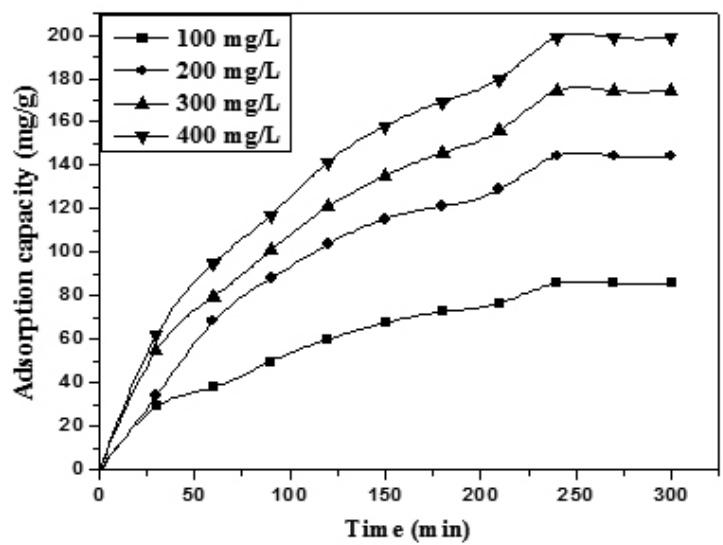

Figure 7. Effect of contact time on 4-chlorophenol biosorption [Different initial 4-CPh concentrations. (ф) $\mathrm{C}_{0}=100 \mathrm{mg} / \mathrm{L},(\bullet) \mathrm{C}_{0}=200 \mathrm{mg} / \mathrm{L},(\boldsymbol{\Delta}) \mathrm{C}_{0}=$ $300 \mathrm{mg} / \mathrm{L}$, (q) $\mathrm{C}_{0}=400 \mathrm{mg} / \mathrm{L} ; \mathrm{pH}=5.0 ;$ biosorbent dosage $=0.4 \mathrm{~g} / 0.1 \mathrm{~L} ;$ contact time $4 \mathrm{~h}$, agitation rate: $220 \mathrm{rpm}, \mathrm{Temp}=25 \pm 1{ }^{\circ} \mathrm{C}$ ]. 


\section{KINETIC STUDIES}

Adsorption kinetics has been proposed to elucidate the adsorption mechanism. The kinetic adsorption data were investigated to understand the dynamics of the adsorption process in terms of the order of the rate constant. Different kinetic models including the pseudo-first-order and pseudo-second-order and were applied for the experimental data to predict the adsorption kinetics.

The comparison was done in between the experimental data, calculated data and the regression coefficient $\left(\mathrm{R}^{2}\right)$. The well known pseudo-first order and pseudosecond order models were employed to fit the data. It may be represented as, ${ }^{26,27}$

$$
\begin{aligned}
& \text { pseudo-first order model : } \quad \log \left(q_{e}-q_{t}\right)=\log q_{e}-\frac{k_{1} t}{2.303} \\
& \text { pseudo-second order model : } \quad \frac{t}{q_{t}}=\frac{1}{k_{2} q_{e}^{2}}+\left(\frac{1}{q_{e}}\right) t
\end{aligned}
$$

Where $\mathrm{q}_{\mathrm{t}}$ is the amount adsorbed at time $\mathrm{t}, k_{1}$ and $k_{2}$ are the kinetic parameters to be determined. The slope and intercept of plot of log ( $\left.\mathrm{q}_{\mathrm{e}}-\mathrm{q}_{\mathrm{t}}\right)$ versus $\mathrm{t}$ were used to determine the pseudo-first order rate constant $k_{1}$. The slope and intercept of plot of $\mathrm{t} / \mathrm{q}$ versus $\mathrm{t}$ were used to calculate the pseudo-second order rate constant $k_{2}$. The kinetic parameters are included Table 2 . The correlation coefficient $\left(R^{2}\right)$ is relatively too low which may be indicative of a bad correlation. In addition, $q$ cal determined from the model is not in a good agreement with the experimental value of $q_{\mathrm{e}}$ exp. Therefore, the adsorption of phenolic compounds onto $A$. leucocephala bark powder is not suitable for the pseudo-second order reaction. Based on higher correlation coefficients and agreement between experimental and calculated $\mathrm{q}_{\mathrm{e}}$ values are closer to unity for pseudo-first-order kinetic model; therefore, the biosorption kinetics could well be approximated more favorably by pseudo-first order kinetics model rather than pseudo-second order kinIn order to quantitatively compare the applicability of each model, a normalized standard deviation $\Delta q(\%)$ was calculated.

Table 2. Biosorption rate constants of phenolic compounds on Acacia leucocephala bark powder.

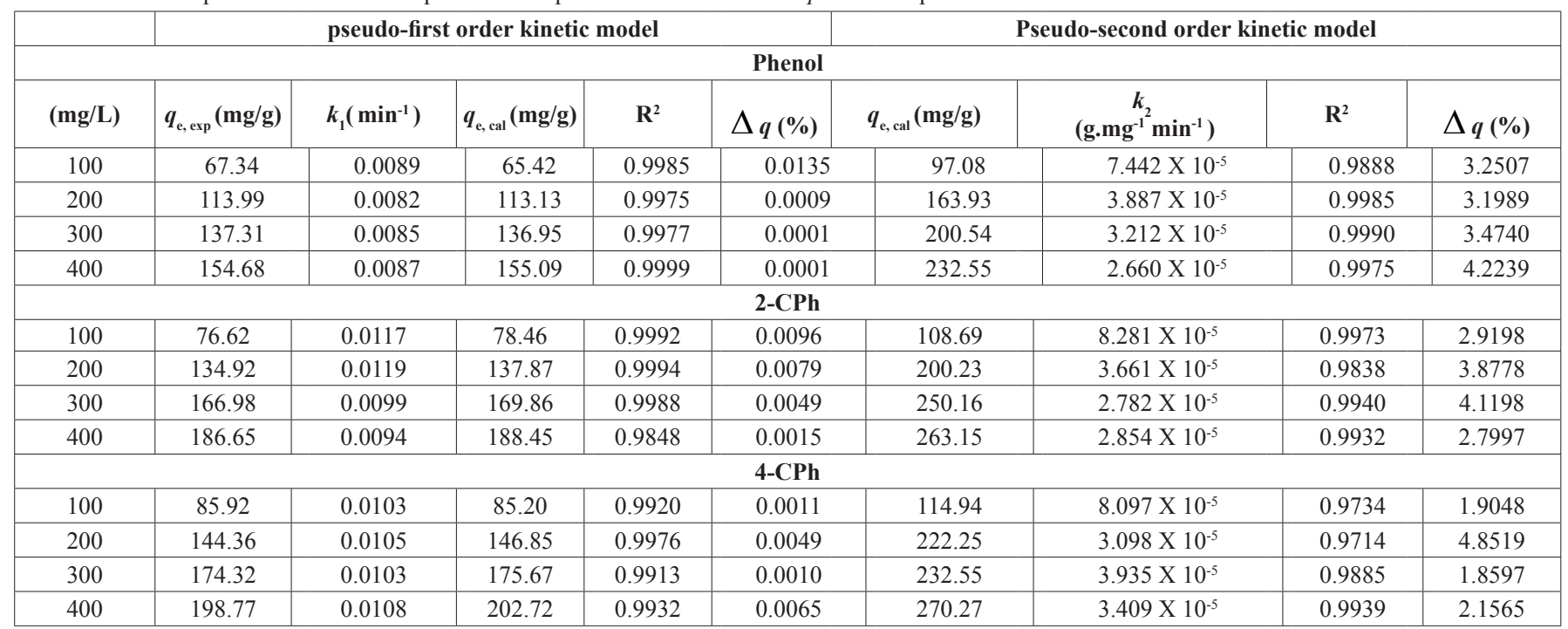

$$
\Delta q(\%)=100 \times \sqrt{\sum \frac{\left[\left(q_{\exp }-q_{c a l}\right) / q_{\exp }\right]^{2}}{(n-1)}}
$$

where the subscripts 'exp' and 'cal' refer to the experimental and calculated values, respectively and $n$ is the number of data points. The lower the value of $\Delta q(\%)$ the model is a better fit for the data. The calculated rate constants for the models, their corresponding regression $\left(\mathrm{R}^{2}\right)$ and normalized standard deviation values are listed in Table 2 . The results suggest that the higher $\mathrm{R}^{2}$ values obtained with the pseudo-first order kinetic model, lower $\Delta$ $q(\%)$ values and the calculated $\mathrm{q}_{\mathrm{e}}(\mathrm{cal})$ values are closer to the experimental data than the calculated values of pseudo-second order kinetic model. From this observation it may be concluded that the adsorption of phenol, 2-CPh and 4-CPh compounds on the A. leucocephala bark powder follows pseudo-first order kinetics.

\section{ADSORPTION ISOTHERM MODELS}

Adsorption isotherm is basically important to describe how adsorbate interacts with adsorbents and is critical in optimizing the use of adsorbents. Although several isotherm equations are available due to their simplicity, three well-known models, Langmuir, Freundlich and Dubinin-Radushkevich (DR) isotherm models were chosen in this study for evaluating the relationship between the amount of phenolic compounds adsorbed onto A. leucocephala bark powder and its equilibrium concentration in aqueous solution.
The Langmuir model assumes that adsorption takes place at specific homogeneous sites on the surface of the adsorbent and also, when a site is occupied by an adsorbate molecule, no further

adsorption can take place at this site. The linear form of the Langmuir isotherm can be represented by the following equation, ${ }^{28}$

$$
\frac{1}{q_{e}}=\frac{1}{Q^{0}}+\left(\frac{1}{b Q^{0}}\right) C_{e}
$$

where $C_{\mathrm{e}}(\mathrm{mg} / \mathrm{L})$ is the equilibrium concentration of the adsorbate, $q_{\mathrm{e}}$ $(\mathrm{mg} / \mathrm{g})$ is the amount of adsorbate adsorbed per unit mass of adsorbent, $\mathrm{Q}^{0}$ and $\mathrm{b}$ are Langmuir constants related to adsorption capacity and rate of adsorption, respectively. The linear plot of $1 / C_{e}$ versus $1 / q_{e}$ indicates that adsorption obeys the Langmuir model.

The most important characteristics of the Langmuir isotherm can be expressed in terms of a dimensionless separation factor $\left(R_{L}\right)$ which is defined as, ${ }^{29}$

$$
R_{L}=\frac{1}{1+b C_{0}}
$$

where $C_{0}(\mathrm{mg} / \mathrm{L})$ is the initial amount of adsorbate and $b(\mathrm{~L} / \mathrm{mg})$ is the Langmuir constant described above. The $R_{\mathrm{L}}$ parameter is considered as more 
reliable indicator of the adsorption. The value of $R_{\mathrm{L}}$ indicates the type of the isotherm to be either unfavorable $\left(R_{\mathrm{L}}>1\right)$, linear $\left(R_{\mathrm{L}}=1\right)$, favorable $\left(0<R_{\mathrm{L}}\right.$ $<1)$ or irreversible $\left(R_{\mathrm{L}}=0\right)$. The value of $R_{\mathrm{L}}$ is less than 1 and great than 0 , suggesting the favourable uptake of phenol, $2-\mathrm{CPh}$ and $4-\mathrm{CPh}$ compounds by A. leucocephala bark powder.

The Freundlich isotherm is given as,

$$
q_{\mathrm{e}}=K_{F} C_{e}^{1 / n}
$$

where $K_{\mathrm{F}}\left((\mathrm{mg} / \mathrm{g})(\mathrm{L} / \mathrm{mg})^{1 / n}\right)$ is roughly an indicator of the adsorption capacity and $(1 / n)$ of the adsorption intensity. Value of $n>1$ represents a favorable adsorption condition. ${ }^{30}$ The linear form of Eq. (9) is

$$
\ln q_{\mathrm{e}}=\ln K_{F}+\left(\frac{1}{n}\right) \ln C_{e}
$$

which will have a straight line with a slope of $1 / n$ and an intercept of $\ln \left(K_{\mathrm{F}}\right)$ when $\ln \left(q_{\mathrm{e}}\right)$ is plotted against $\ln \left(C_{\mathrm{e}}\right)$.

Another model for the analysis of isotherms of a high degree of rectangularity is Dubinin-Radushkevich isotherm has the following form, ${ }^{31}$

$$
q_{e}=q_{s} \exp \left(-B \varepsilon^{2}\right)
$$

where $\mathrm{q}_{\mathrm{s}}$ is the Dubinin-Radushkevich monolayer capacity $(\mathrm{mg} / \mathrm{g}), \beta$ a constant related to sorption energy, and $\varepsilon$ is the Polanyi potential which is related to the equilibrium concentration as follows

$$
\varepsilon=R T \ln \left[1+\frac{1}{C_{e}}\right]
$$

where $\mathrm{R}$ is the gas constant $(8.314 \mathrm{~J} / \mathrm{mol} \mathrm{K})$ and $\mathrm{T}$ is the absolute temperature. The constant $B$ gives the mean free energy $E$ of adsorption per molecule of the adsorbate when it is transferred to the surface of the solid from infinity in the solution and can be computed by using the relationship:

$$
E=\frac{1}{\sqrt{2 B}}
$$

A plot of $\ln (q)$ versus $\varepsilon^{2}$ enables the constants $q$ and $E$ to be determined. The parameters of the three isotherms were computed and listed in Since the value of $R^{2}$ nearer to 1 indicates that the respective equation better fits the experimental data. The experimental data yielded excellent fits within the following isotherms order: Langmuir $>$ Freundlich $>$ Dubinin-Radushkevich, based on its $\mathrm{R}^{2}$ values. All the evaluated equilibrium models gave good fit to the experimental data, it can be concluded that the Langmuir is the best model describing adsorption of phenolic compounds on the A. leucocephala bark powder, as it gave the maximum $\mathrm{R}^{2}$ value among the considered models. The comparison of maximum monolayer adsorption capacities of different adsorbents obtained from different sources are listed in Table 4 along with the values obtained in the present study.
Table 3. Isotherm Parameters of Langmuir, Freundlich and D-R isotherms for biosorption of phenol, 2-CPh and 4-CPh on Acacia leucocephala bark powder

\begin{tabular}{|c|c|c|c|}
\hline \multirow{2}{*}{ Isotherm model } & \multicolumn{3}{|c|}{ Adsorbates } \\
\cline { 2 - 4 } & Phenol & 2-CPh & 4-CPh \\
\hline Langmuir & & & \\
\hline $\mathrm{Q}^{0}$ & 94.33 & 147.05 & 181.81 \\
\hline $\mathrm{b}$ & 0.0509 & 0.0283 & 0.0385 \\
\hline $\mathrm{R}^{2}$ & 0.9985 & 0.9941 & 0.9975 \\
\hline Freundlich & & & \\
\hline $\mathrm{K}_{\mathrm{F}}$ & 6.0201 & 4.5540 & 7.1203 \\
\hline $\mathrm{n}$ & 1.4662 & 1.1976 & 1.1767 \\
\hline $\mathrm{R}^{2}$ & 0.9793 & 0.9827 & 0.9880 \\
\hline $\begin{array}{c}\text { Dubinin- } \\
\text { Raduskvich }\end{array}$ & & & \\
\hline $\mathrm{q}_{\mathrm{s}}$ & 3.9018 & 4.0985 & 4.1233 \\
\hline $\mathrm{E}$ & 28.86 & 25 & 40.82 \\
\hline $\mathrm{R}^{2}$ & 0.8543 & 0.8527 & 0.8091 \\
\hline & & & \\
\hline
\end{tabular}

Table 4. Maximum Adsorption Capacities, $\mathrm{Q}^{0}(\mathrm{mg} / \mathrm{g})$, for the Adsorption of Phenol, 2-CPh and 4-CPh compounds by Various Adsorbents.

\begin{tabular}{|l|l|l|l|l|}
\hline \multirow{2}{*}{ Sorbent } & \multicolumn{3}{c|}{ Adsorbates, $\mathrm{Q}^{0}(\mathrm{mg} / \mathrm{g})$} & \\
\cline { 2 - 5 } & Phenol & 2-CPh & $4-\mathrm{CPh}$ & References \\
\hline $\begin{array}{l}\text { Organomodified } \\
\text { bentonite }\end{array}$ & 333 & - & - & 14 \\
\hline Bentonite \& Perlite & - & - & $\begin{array}{l}10.63 \& \\
5.84\end{array}$ & 32 \\
\hline $\begin{array}{l}\text { manganese nodule } \\
\text { leached residue }\end{array}$ & 28.50 & - & - & 33 \\
\hline $\begin{array}{l}\text { Sugarcane bagasse } \\
\text { fly ash }\end{array}$ & 23.83 & - & - & 34 \\
\hline $\begin{array}{l}\text { Brown alga Sargassum } \\
\text { muticum }\end{array}$ & 4.6 & 79.0 & 251.0 & 35 \\
\hline CS/Ab blended beads & 156 & 204 & 278 & 36 \\
\hline Date Seed Carbon & 138.88 & - & - & 37 \\
\hline $\begin{array}{l}\text { Activated sewage } \\
\text { sludge }\end{array}$ & 29.46 & - & - & 38 \\
\hline $\begin{array}{l}\text { commercial activated } \\
\text { carbon }\end{array}$ & 49.72 & - & - & 39 \\
\hline CS/CA blended beads & 109 & 97 & - & 40 \\
\hline fly ash & 3.85 & - & - & 41 \\
\hline Rice husk char & 7.91 & - & 36.23 & 42 \\
\hline $\begin{array}{l}\text { A. leucocephala } \text { bark } \\
\text { powder }\end{array}$ & 94.33 & 147.05 & 181.81 & Present study \\
\hline
\end{tabular}

\section{CONCLUSIONS}

The present work elucidates that the A. leucocephala bark powder has proven to be a promising material for the removal of phenol and its derivatives from aqueous medium.

- The $\mathrm{pH}$ played an obvious effect on the phenolic compounds biosorption capacity onto A. leucocephala bark powder. An increase of the solutions $\mathrm{pH}$ leads to a significant increase in the biosorption capacities of phenolic compounds on the A. leucocephala bark powder, maximum biosorption capacity occurred at neutral $\mathrm{pH}$.

- The results showed that the good correlation coefficients and the agreement between experimental and calculated values of $\mathrm{q}_{\mathrm{e}}$ and lower $\Delta$ $q(\%)$ values showed that the phenolic compounds adsorption followed pseudo-first- order kinetics.

- Biosorption equilibrium data was better described by the Langmuir isotherm model than the Freundlich and D-R adsorption isotherm model.

- The A. leucocephala bark powder showed a high adsorption capacity of phenol, 2-CPh and 4-CPh (94.33 mg/g, $147.05 \mathrm{mg} / \mathrm{g}$ and $181.81 \mathrm{mg} / \mathrm{g})$ revealing that $A$. leucocephala bark powder could be employed as a promising biosorbent for removal of phenolic compounds adsorption. 
All the above results suggested that the A. leucocephala bark powder is an effective and alternative biosorbent, but also it is highly efficient for removal of phenol, 2-CPh and 4-CPh compounds from aqueous medium in terms of high adsorption capacity, economically viable; abundantly and locally available.

\section{REFERENCES}

1. M. Khalid, G. Joly, A. Renaud, P. Magnoux, Ind. Eng. Chem. Res. 43, $5275,(2004)$

2. G. Bayramoglu, M. Y. Arica, J. Hazard. Mater. 156, 148, (2008)

3. Tepe, O.; Dursun, A. Y. J. Hazard. Mater. 151, 9, (2008)

4. F. A. Banat, V. Al-Bashir, S. Al-Asheh, O. Hayajneh, Environ. Pollut. 107, 391, (2000)

5. A. Knop, L. A. Pilato, Phenolic Resins-Chemistry, Applications and Performance, Springer-Verlag, 1985.

6. WHO (World Health Organization), Guidelines for Drinking Water Quality (vol. II): Health Criteria and Supporting Information, World Health Organization, Geneva, Switzerland, 1984.

7. N. N. Dutta, S. Brothakur, R. Baruaha, Water. Environ. Res. 70, 4, (1998)

8. J. S. Ra, S.-Y. Oh, B. C. Lee, S. D. Kim, Environ. Inter. 34, 184, (2008)

9. A. H. Mollah, C. W. Robinson, Water Res. 30, 2901, (1996)

10. A. R. Khan, T. A. Al-Bahri, A. Al-Haddad, Water Res. 31, 2102 (1997)

11. D. Batabyal, A. Sahu, S. K. Chaudhuri, Sep Sci Technol. 5, 179 (1995)

12. E. Mona, R. Zein, R. Kurniadi, I. Kurniadi, Environ. Technol. 18, 355, (1997)

13. T. Viraraghavan, F. De Maria Alfaro, J. Hazard. Mater. 57, 59, (1998)

14. S. Hasan Basri, O. Duygu, G. Ali, D. Celal, S. Mustafa, J. Hazard. Mater. $172,353,(2009)$

15. A. M. Li, Q. X. Zhang, G. C. Zhang, J. L. Chen, Z. H. Fei, F. Q. Liu, Chemosphere. 47, 981, (2002)

16. B. C. Pan, X. Zhang, W. M. Zhang, J. Z. Zheng, B. J. Pan, J. L. Chen, Q. X. Zhang, J. Hazard. Mater. 121, 233, (2005)

17. V. K. Garg, R. Gupta, A. Bala, R. Kumar, Bioresour. Technol. 89, 121, (2009)

18. M. A. Abdulkarim, N. A. Darwish, Y. M. Magdy, A. Dwaidar, Eng. Life Sci. 2, 161, (2002)
19. J. R. Rao, T. Viraraghavan, Bioresour. Technol. 85, 165, (2002)

20. R. Chakravarty, D. C. Rupainwar, Environ. Technol. 20, 397, (1999)

21. G. Vazquez, J. Gonzalez-A lvarez, S. Freire, M. Lopez-Lorenzo, G. Antorrena, Bioresour. Technol. 82, 247, (2002)

22. I. P. Bras, L. Santos, A. Alves, Environ. Sci. Technol. 33, 631, (1999)

23. G. Vazquez, J. Gonzalez-A lvarez, A. I. Garcia, M. S. Freire, G. Antorrena, Bioresour. Technol. 98, 1535, (2007)

24. M. Venkata Subbaiah, Y. Vijaya, N. Siva Kumar, A. Subba Reddy, A. Krishnaiah, Chem Eng. J. 157, 357, (2010)

25. M. Venkata Subbaiah, Y. Vijaya, N. Siva Kumar, A. Subba Reddy, A. Krishnaiah, Colloids Surfaces B. 74, 260, (2009)

26. Y. S. Ho, G. McKay, Water Res. 33, 578, (1999)

27. Y. S. Ho, J. Hazard. Mater. 136, 681, (2006)

28. V. K. Gupta, I. Ali, V. K. Saini, Environ. Sci. Technol. 38, 4012, (2004)

29. N. Siva Kumar, V. M. Boddu, A. Krishnaiah, Adsorp. Sci. Technol. 27, 31 , (2009)

30. G. McKay, H. S. Blair, J. R. Gardner, J. Appl. Polym. Sci. 27, 3043, (1982)

31. M. M. Dubinin, L. V. Radushkevich, Chem. Zent. 1, 875, (1947)

32. B. Koumanova, P. Peeva-Antova, J. Hazard. Mater. 90, 229, (2002)

33. K. M. Parida, A. C. Pradhan, J. Hazard. Mater. 173, 758, (2010)

34. V. C. Srivastava, M. M. Swamy, I. D. Mall, B. Prasad, I. M. Mishra, Colloids Surf. A: Physicochem. Eng. Aspects. 272, 89, (2006)

35. E. Rubin, P. Rodriguez, R. Herrero, M. Sastre de Vicente, J. Chem. Technol. Biotechnol. 81, 1093, (2006)

36. N. Siva Kumar, M. Venkata Subbaiah, A. Subba Reddy, A. Krishnaiah, J. Chem. Technol. Biotechnol. 84, 972, (2009)

37. S. M. Mane, A. K. Vanjara, M. R. Sawant, J. Chin. Chem. Soc. 52, 1117 , (2005)

38. M. Otero, F. Rozada, L. F. Calvo, A. I. Garca, A. Moran, Dyes. Pigm. 57, $55,(2003)$

39. B. Ozkaya, J. Hazard. Mater. 129, 158, (2006)

40. N. Siva Kumar, S. Kalyani, V. M. Boddu, A. Krishnaiah, J. Hazard. Mater. $162,482,(2008)$

41. B. K. Singh, N. S. Rawat, J. Chem. Technol.Biotechnol. 16, 307, (1994)

42. M. Ahmaruzzaman, D. K. Sharma, J. Colloid Interface Sci. 287, 14, (2005). 